\title{
Sistem Informasi Pengolahan Data Pemungutan Pajak Bumi dan Bangunan
}

\section{Data Processing Information System for Land and Building Tax Collection}

\author{
Cepi Rahmat Hidayat ${ }^{1}$, Doni Ramdanis ${ }^{2}$ \\ ${ }^{1,2}$ STMIK Tasikmalaya; Jalan RE Martadinata 272A Tasikmalaya, (0265)310830 \\ STMIK Tasikmalaya, Tasikmalaya. \\ 1ranvix14@gmail.com, ${ }^{2}$ doniramdani18@gmail.com
}

\begin{abstract}
Abstrak
Sistem pengolahan data pemungutan pajak bumi dan bangunan di kelurahan talagasari masih banyak ditemukan kekurangan dalam pelaksanaannya, hal tersebut dikarenakan sistem pengolahan data masih dikerjakan secara konvensiaonal yaitu dilakukan pencatatan dalam buku besar. Sistem pengolahan seperti itu menjadi kurang efektif dan efisien, contohnya dalam pencarian data ataupun pembuatan laporan bulanan ataupun tahunan, selain itu juga kemungkinan terjadinya kesalahan pen ataupun perhitungan sangat besar. Dalam penelitian ini peneliti menggunakan metode deskriptif dengan pendekatan kualitatif dan model perancangan SDLC (Software Development Life Cycle). Sedangkan teknik pengumpulan data yang peneliti lakukan adalah observasi, studi literatur, dan wawancara. Hasil dari penelitian ini adalah sistem pemungutan pajak bumi dan bangunan yang terkomputerisasi di Kelurahan Talagasari Kawalu dengan adanya sistem informasi tersebut diharapkan dapat menghasilkan output informasi cepat, tepat dan akurat dalam melakukan pelayanan terhadap masyarakat sehingga kinerja bisa lebih efektif dan efisien.
\end{abstract}

Kata kunci - Sistem Informasi, Pemungutan Pajak Bumi dan Bangunan, Model SDLC

\begin{abstract}
Data Processing Systems Land and Building Tax Collection in the village Talagasari Many Still Lack discovered hearts implementation, HAL is because the system still worked BY Data Processing That is recording on conventional hearts big book. Processing systems such as ITU Becoming Less Effective and efficient process, for example hearts Data Searches or Preparation of Monthly or Annual Report, in addition to IT ALSO possibility of writing or a calculation error is very big. In this study Label writer uses descriptive method WITH qualitative approach and design model (Software Development Life Cycle) SDLC. While data collection techniques Authors do What is observation, literature study, and interviews. Results Of Research Husband Is a Tax Collection System The computerized land and building in the Village Talagasari Kawalu WITH Information System is expected to produce an output CAN Information Fast, Precise and Accurate hearts do Client Service 'society that goes down the boarding costs can more effectively and efficiently process.
\end{abstract}

Keywords - Information, Land and Building Tax Collection, Model SDLC

\section{PENDAHULUAN}

Penggunaan komputer dalam kehidupan kita telah meluas tidak hanya terbatas di lingkungan perkantoran, sekolah maupun intansi pemerintahan. Komputer merupakan salah satu alat yang sangat penting dalam perancangan sebuah sistem, dimana hasil perancangan sistem tersebut harus dapat berfungsi sebagai sarana penunjang untuk membantu proses pengolahan data dengan efektif. komputer mempunyai pengaruh besar dalam membantu dan mempercepat pekerjaan untuk menyajikan suatu laporan ataupun pengolahan data. Selain komputer, 
dibutuhkan juga suatu sistem informasi yang dapat menunjang kegiatan bagi suatu intansi pemerintah ataupun perusahaan.

Setiap masyarakat yang berada dalam suatu negara pasti akan berurusan dengan pajak, karena pajak merupakan aset penting bagi negara dan merupakan salah satu faktor yang sangat penting untuk pembangunan sebuah negara. Setiap wajib pajak yang memiliki objek pajak bumi dan bangunan, baik besar maupun kecil akan dikenakan pajak sesuai kemampuan dan keadaannya [1] Variabel kesadaran wajib pajak sangat mungkin dikaitkan dengan kepatuhan membayar pajak. Kesadaran itu muncul berdasarkan motivasi wajib pajak.[2] Kantor Kecamatan yang bertugas melayani masyrakat wajib memungut biaya berupa pajak, khususnya pemungutan pajak bumi dan bangunan yang bertujuan untuk meningkatkan kesadaran masyrakat dalam membayar pajak bumi dan bangunan dan memudahkan masyrakat dalam proses pembayaran. Pajak bumi dan bangunan adalah pajak yang dikenakan terhadap bumi dan bangunan [3].

Sistem Informasi adalah sejumlah komponen (manusia, komputer, teknologi informasi, dan prosedur kerja), ada sesuatu diproses (data menjadi informasi), dan dimaksudkan untuk mencapai tujuan tertentu [4]. Input yang masuk dalam sistem akan diproses dan diolah sehingga menghasilkan output [5] sebuah sistem informasi mempunyai peran penting dalam kegiatan yang terjadi dalam sebuah intansi pemerintah, antara lain dalam penyimpanan, pengolahan dan pembuatan laporan keungan pemungutan pajak. Maka dari itu intansi pemerintah khususnya di kelurahan ingin membuat perubahan pada sistem yang di gunakan untuk mengelola data hasil pemungutan pajak bumi dan bangunan. Dimana proses tersebut masih dilakukan secara konvensional yaitu menggunakan pencatatan dalam buku besar.

Karena sistem yang sedang berjalan belum terkomputerisasi maka proses pencarian dan pembuatan laporan membutuhkan waktu yang cukup lama karena dilakukan secara manual. selain itu penggunaan sistem yang sedang berjalan banyak juga ditemukan kesalahan-kesalahan dalam pencatatan maupun perhitungan hal tersebut karena belum adanya sistem terkomputerisasi yang dapat meminimalisir kesalahan penginputan serta melakukan perhitungan secara otomatis. Maka dari itu perlu adanya sebuah sistem informasi pengolahan data pemungutan pajak bumi dan bangunan di Keluarahan Talaga sari Kawalu

Sistem Informasi yang akan dibangun diharapkan mampu memberikan pelayanan yang maksimal kepada masyarakat yaitu pada pengolahan data pemungutan pajak bumi dan bangunan. Sehingga masyarakan petugas kelurahan bisa jauh lebih efektif dan efisien dalam mengelola segala bentuk transaksi pemungutan pajak bumi dan bangunan.

\section{METODE PENELITIAN}

Metode penelitian pada dasarnya merupakan cara ilmiah mendapatkan data dengan tujuan dan kegunaan tertentu. Untuk membantu mempermudah pengumpulan dan pengolahan data, dalam penelitian ini digunakan metode diskriptif untuk dapat melengkapi dan mengumpulkan data yang dibutuhkan. Adapun teknik pengumpulan data yang digunakan yaitu dengan melakukan pengamatan langsung (obsevasi) ke Kelurahan Talagasari Kawalu untuk melihat secara langsung proses pengolahan data yang dilakukan juga dengan melakukan wawancara kepada pihak-pihak terkait yang dapat memberikan informasi.

Untuk metode perancangangan menggunakan System Development Life Cycle (SDLC) adalah salah satu metode pengembangan sistem informasi yang popular pada saat sistem informasi pertama kali dikembangkan [6]. merupakan sebuah metodologi dalam pembangunan atau pengembangan sistem, System Development Life Cycle memberikan kerangka kerja yang konsisten terhadap tujuan yang diinginkan dalam pembangunan dan pengembangan system. Adapun tahapan-tahapan SDLC yang dilakukan yaitu dengan melakukan investigasi untuk mengetahui kekurangan pada sistem yang sedang berjalan juga melihat peluang untuk mengembangkan sistem yang berjalan sehingga masalah yang ada dapat teratasi. Menganalisis 
kebutuhan yang diperlukan oleh Kelurahan Talagasari Kawalu, tahap-tahapan yang dilakukan sebagai berikut :

1. Tahap investigasi investigasi untuk mengetahui kekurangan pada sistem yang sedang berjalan juga melihat peluang untuk mengembangkan sistem yang berjalan sehingga masalah yang ada dapat teratasi.

2. Tahap analisis bertujuan untuk mencari kebutuhan yang diperlukan oleh Kelurahan Talagasari Kawalu.

3. Tahap desain untuk menentukan koponen yang akan dibuat baik untuk menghasilkan informasi yang di butuhkan.

4. Tahap code merupakan tahapan untuk membuat program aplikasi ( pengkodean program) yang akan dibuat dengan menggunakan Visual Basic 6.0.

5. Tahap implementasi untuk melakukan pengujian program aplikasi yang telah dibuat juga pelatihan terhadap petugas koperasi yang akan menggunakan program aplikasi ini.

6. Tahapan perawatan ( maintenance).

\subsection{Analisis dan Pembahasan Masalah}

Menganalisa dari sistem yang berjalan dengan analisis kelemahan sistem yang ada,serta mengumpulkan kebutuhan-kebutuhan sistem yang akan dibangun [7]. Berdasarkan hasil peninjauan terhadap kekurangan dan kekeliruan sistem yang sedang berjalan, dimana pengolahan data pemungutan pajak bumi dan bangunan masih menggunakan penhinputan dan pen yimpanan menggunakan buku sehingga tidak menjamin keamaman dan kemudahan dalam pencarian data. Maka diperlukan sistem terkomputerisasi yang dapat digunakan untuk penyimpanan dan pencarian data secara cepat dan akurat, sehingga dapat mempermudah pekerjaan.Dalam perancangan system, peneliti menggunakan Context Diagram, Data Flow Diagram dan Entity Relationship Diagram untuk menggambarkan Data Pemungutan Pajak Bumi dan Bangunan ini.

\subsubsection{Context Diagram}

Diagram ini menggambarkan sistem secara umum [8]. Data-data yang digunakan untuk diolah menjadi informasi dalam sistem ini merupakan data primer (resmi) yang diperoleh dari instansi berwenang yaitu Kelurahan Talagasari Kawalu. Pada sistem pemungutan pajak bumi dan bangunan terdapat lima entitas yaitu 1)Admin sebagain petugas pengolah data pemungutan wajib pajak 2) Bagian Pimpinan Kelurahan melaporkan data pemungutan pajak bumi dan bangunan. 3) Bagian wajib pajak merupakan orang yang dikenakan wajib pajak inputannya adalah lembar SPPT 4) kolektor menginput lembar SPT.

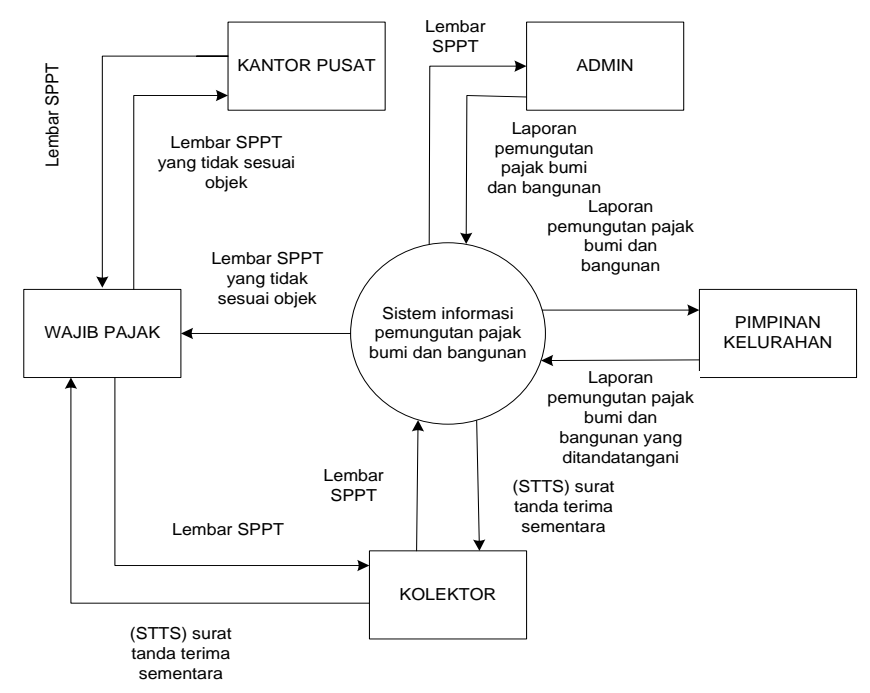

Gambar 1.Context Diagram Sistem 


\subsubsection{Data Flow Diagram}

a. Diagram Level 0

Diagram ini menggambarkan alur data yang mengalir dalam sistem. Data berasal dari wajib pajak yang nantinya di serahkan ke bagian admin pengurus pajak bumi dan bangunan. Data tersebut dapat di gambarkan menggunakan diagram arus data level 0 seperti yang terlihat pada gambar 2 berikut ini.

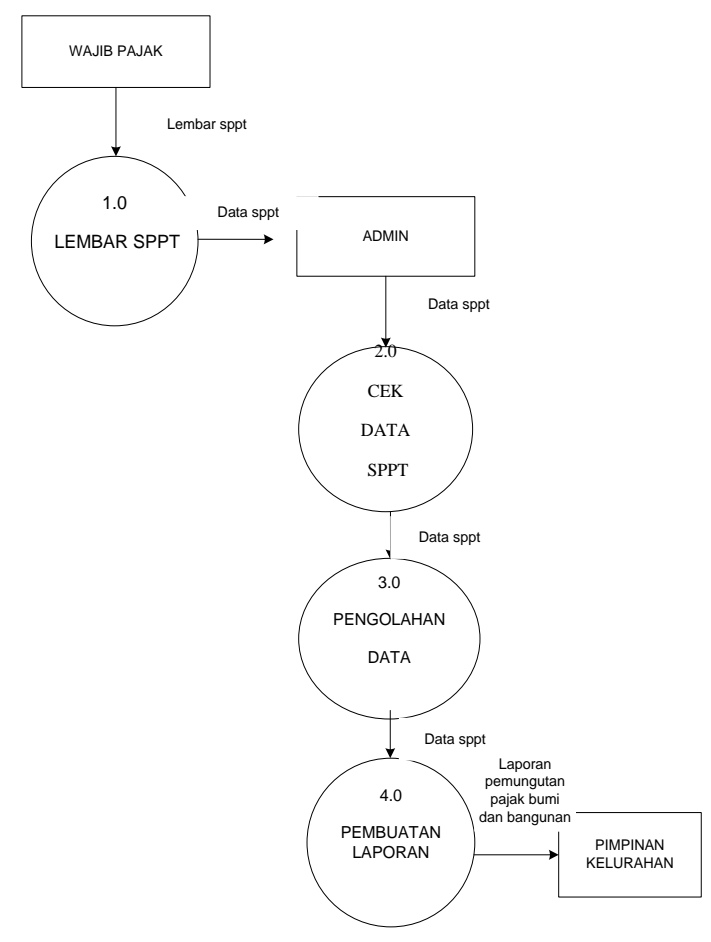

Gambar 2. DFD Level 0

Diagram diatas menggambarkan terdapat tiga entitas dan empat proses yaitu proses lembar SPPT, proses pengecekan data SPPT, proses pengolahan data dan pembuatan laporan

b. DFD Level 1 proses 3.0

Diagram ini menggambarkan proses pengolahan data pemungutan pajak bumi dan bangunan. yang berisi nama, tempat tanggal lahir, dan lain - lain. seperti terlihat pada gambar 3 berikut ini. 


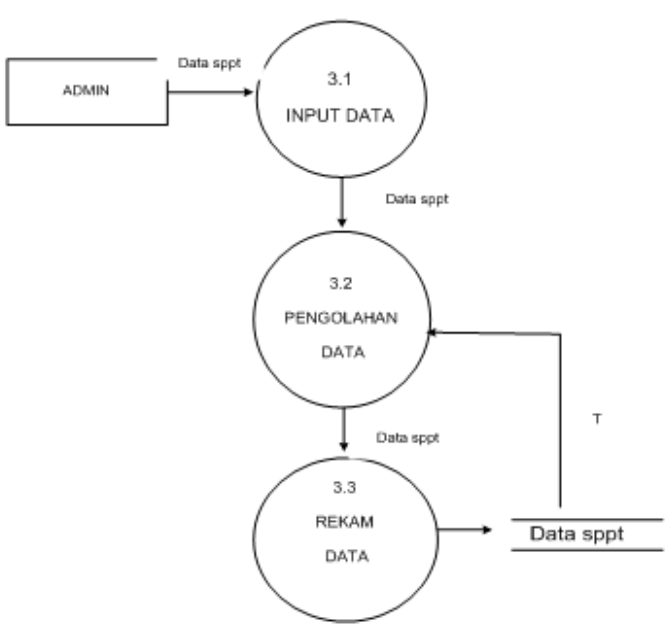

\section{Gambar 3. DFD Level 1 Proses 3}

Diagram diatas menggambarkan terdapat dua entitas dan tiga proses yaitu proses input data SPPT kemudian pengolahan perhitungan dan selanjutnya menyimpan data SPPT ke dalam penyimpanan data SPPT.

c. DFD Level 4 proses 4.0

Diagram ini menggambarkan proses pengolahan data pemungutan pajak bumi dan bangunan. Data yang didapat dari pemilik sppt selanjutnya akan diproses. seperti terlihat pada gambar 3 berikut ini.

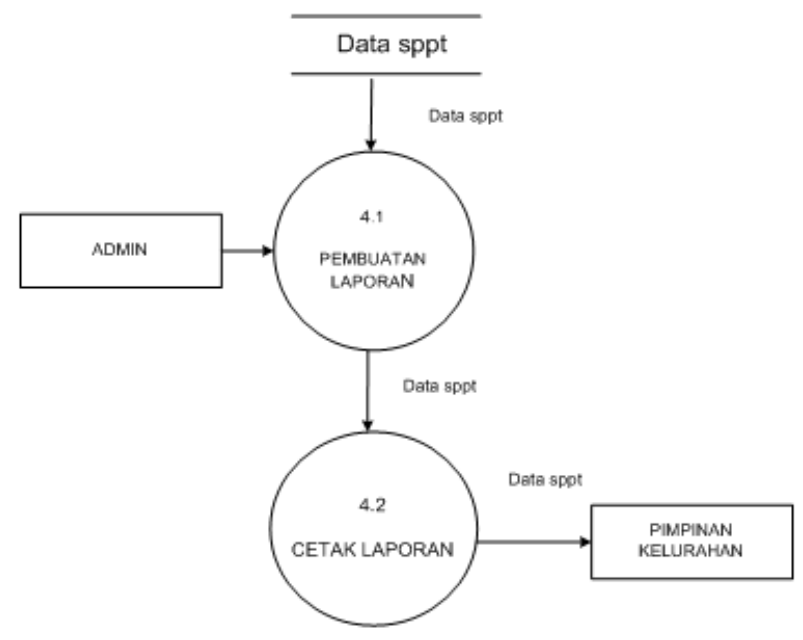

Gambar 4. DFD Level 4 proses 4.0

Pembuatan Laporan Data pemungutan Pajak Bumi dan Bangunan

Diagram diatas menggambarkan terdapat dua entitas dan dua proses yaitu proses pembuatan laporan yang dilakukan oleh admin yang mengambil data dari data SPPT kemudian masuk ke proses cetak yang selanjutnya outputnya dilihat oleh pimpinan kelurahan. 


\subsubsection{Perancangan Database}

Perancangan database secara logis menggunakan Entity Relationship Diagram.Entity Relationship Diagram merupakan model entity relationship yang berisikomponen-komponen himpunan entitas dan himpunan relasi yang masing-masing dilengkapi dengan atribut yang merepresentasikan seluruh fakta dari masalah yang ditinjau.

Sementara data yang sudah ada ditransformasikan dengan memanfaatkan perangkat konseptual menjadi diagram data kemudian dilakukan implementasi rancangan databasenya. Penggunaan konsep database memberikan banyak kemudahan, salah satunya pada proses pencarian (searching) data, sehinggawaktu penyelesaian pekerjaan bisa lebih efisien.

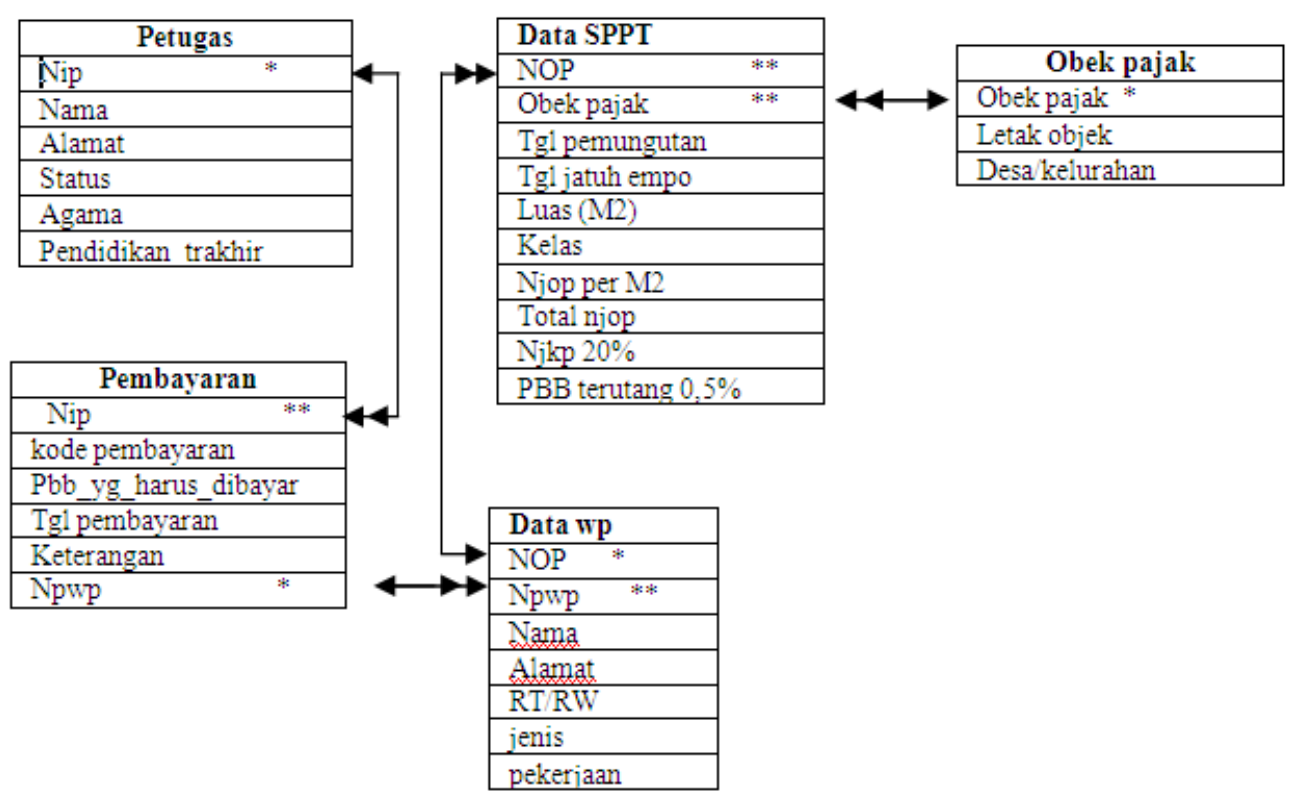

Gambar 5. Relasi Tabel

Gambar 5 menggambarkan implementasi rancangan database dengan menampilkan lima relasi tabel. Antar tabel tersebut saling berelasi satu sama lain sesuai dengan kebutuhan aplikasi yang dirancang. Dari tabel tersebut terlihat jelas menunjukan data-data yang digunakan untuk membangun aplikasi pengolahan data pemungutan pajak bumi dan bangunan ini.Tabel data petugas berisi informasi nip, nama, alamat dan lain-lain. Selain itu, tabel pembayaran juga bisa digunakan untuk menganalisis dan menentukan tanggal pembayaran pajak tersebut[9].

\section{HASIL DAN PEMBAHASAN}

Setelah membuat rancangan database, langkah selanjutnya adalah membuat rancangan tampilan Aplikasi Pengolahan Data Pemungutan pajak bumi dan bangunan di kelurahan Talagasari Kawalu Kota Tasikmalaya. Rancangan tampilan aplikasi dibuat denganmenggunakan Microsoft visual basic 6.0.

1. Tampilan Halaman Utama

Tampilan pertama program aplikasi merupakan halaman pembuka yang berisi menu untuk menggunakan program. Pada halaman utama program aplikasi, untuk mengaktifkannya user harus login terlebih dahulu. Tampilah halaman utama dapat terlihat pada gambar berikut ini. 


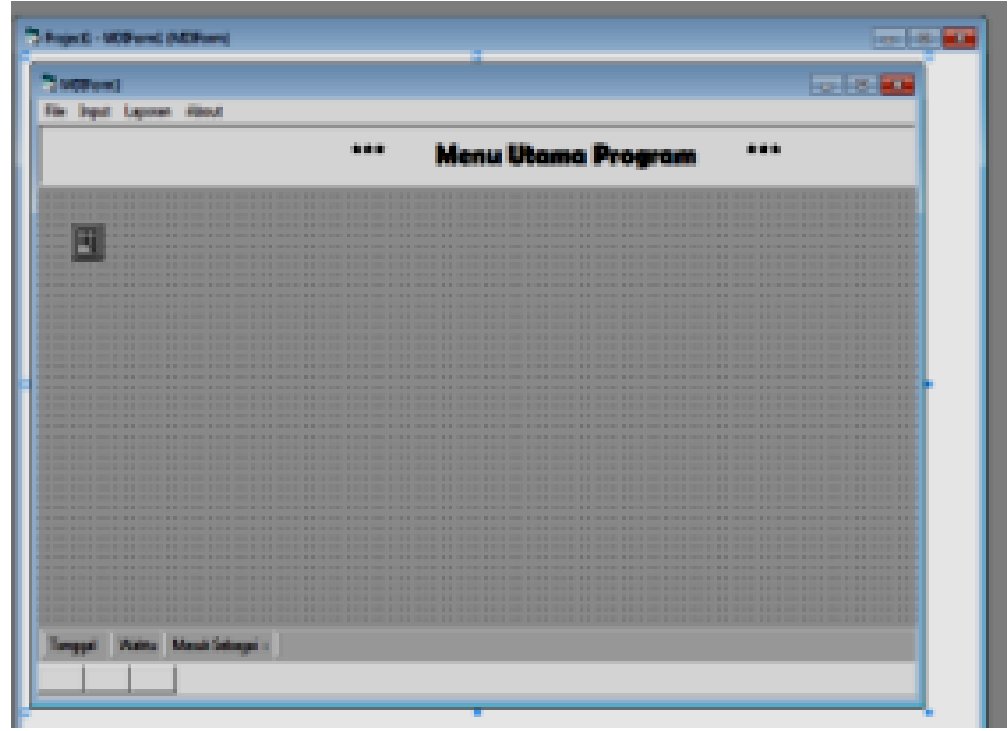

Gambar 6.Tampilan Menu Utama

2. Tampilan input data pemungutan pajak bumi dan bangunan

Pada input data pemungutan pajak bumi dan bangunan ini dapat kita inputkan data yang berisi nama, alamat dan laian - lain. Tampilah input data Petugas dapat terlihat pada gambar berikut ini.

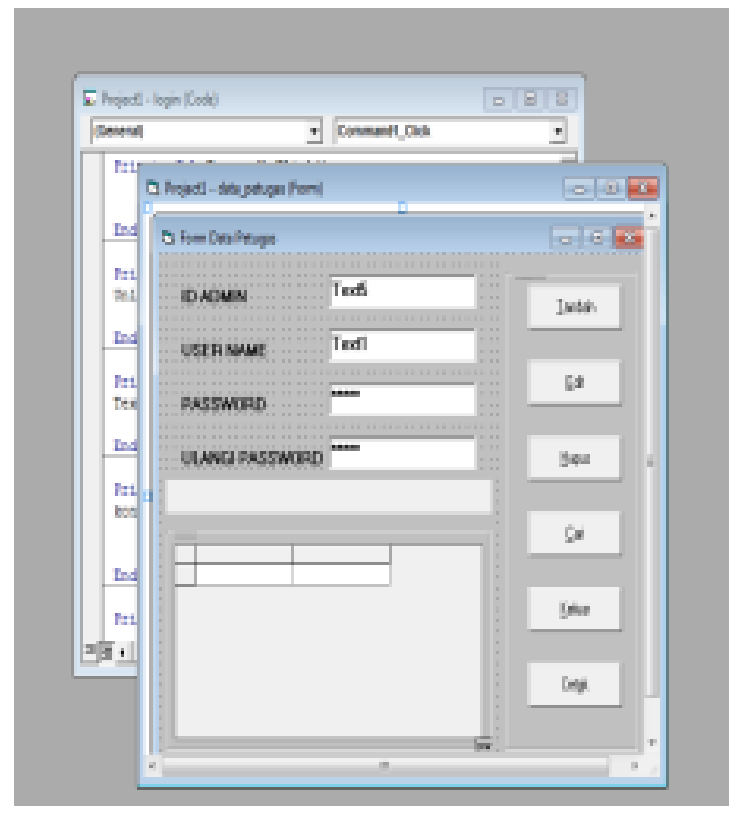

Gambar 7.Tampilan Input Data Petugas

3. Tampilan input data Wajib Pajak

Pada input data Wajib Pajak ini kita dapat menginputkan dan nama wajib pajak dan lain-lain. Tampilah input data Wajib Pajak dapat terlihat pada gambar berikut ini. 


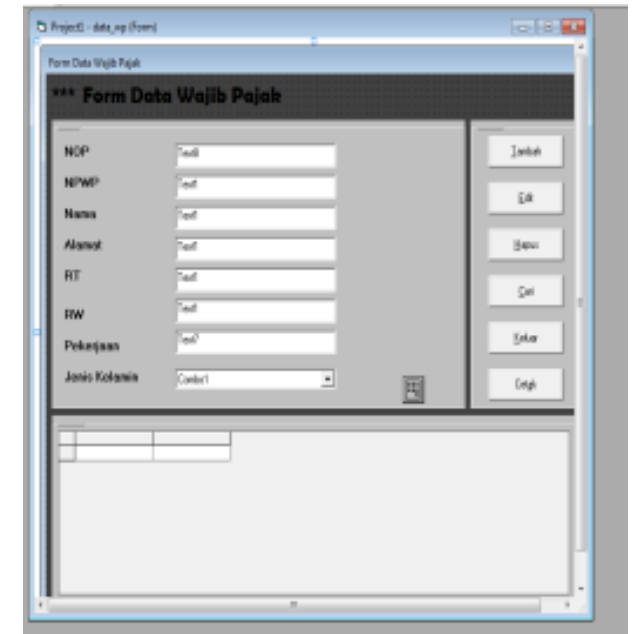

Gambar 8.Tampilan Input Data Wajb Pajak

4. Tampilan input data Objek

Tampilaninidapatkitainputkanobjek pajak.Tampilah data objek pajak dapat terlihat pada gambar berikut ini.

5. Tampilan input SPPT

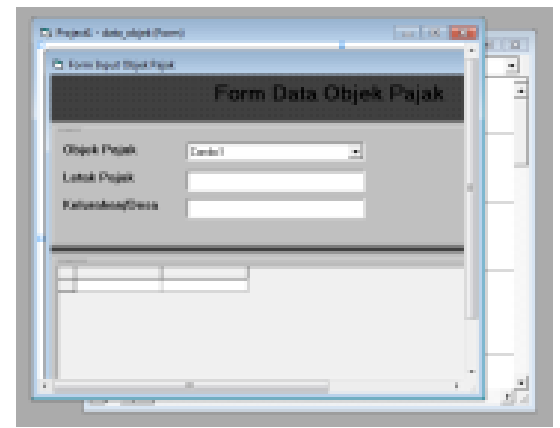

Gambar 9.Tampilan Input Data Objek

Form ini merupakan form untuk mengisi data SPT dan tampilana data SPT dapat terlihat pada gambar berikut ini.

6. Tampilan Login

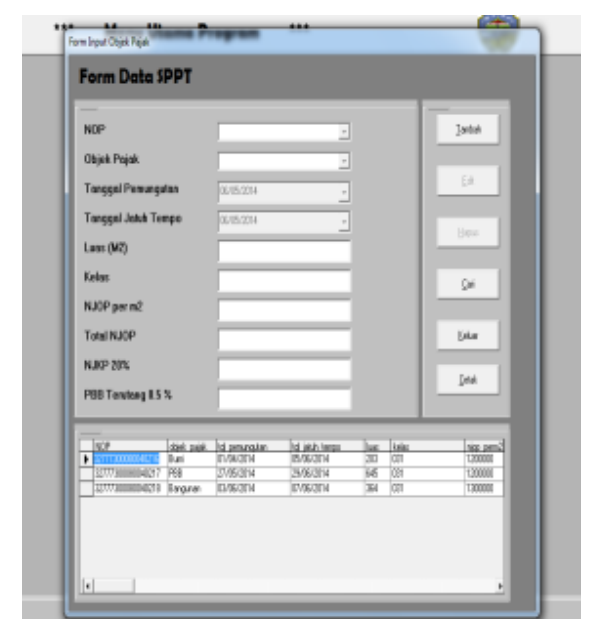

Gambar 10.Tampilan Input Data SPPT 
Login digunakan untuk dapat merubah database, baik itu memasukan data baru, mengupdate ataupun menghapusnya. Tanpa melakukan login, user tidak dapat melakukan proses editing. Berikut tampilan login pengolahan data pemungutan pajak bumi dan bangunan.

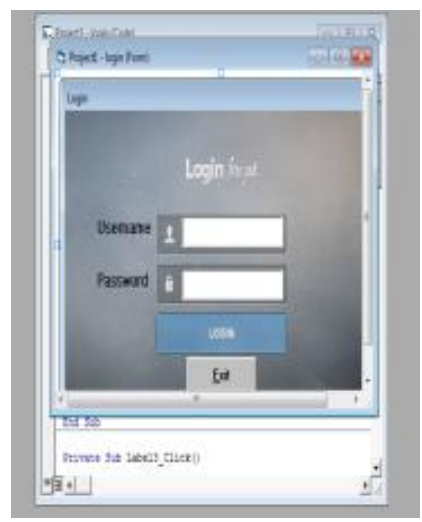

Gambar 11.Tampilan Login

\section{KESIMPULAN}

Berdasarkan hasil penelitian yang telah dilakukan melalui tahapan analisis, pembuatan sistem dan implementasi sistem, maka hasilnya dapat disimpulkan sebagai berikut :

1. Dengan dikembangkannya sistem sistem informasi pemungutan pajak bumi dan bangunan ini, dapat memudahkan petugas kelurahan dalam mengelola pajak bumi dan bangunan secara cepat, tepat dan akurat.

2. Memberikan pelayanan yang maksimal bagi masyarakat khususnya dalam transaksi pembayaran pajak bumi dan bangunan .

3. Pembuatan laporan yang berhubungan dengan pemungutan pajak bumi dan bangunan menjadi lebih praktis.

\section{SARAN}

Adapun saran yang dapat diambil guna pengembangan sistem lebih lanjut adalah sebagai berikut :

1. Fasilitas backup data otomatis perlu dibuat agar dapat meminimalisir kehilangan data atau kerusakan database, sehingga ketika terjadi sesuatu hal yang tidak diinginkan maka data masih bisa terselamtkan.

2. Pemberian hak akses yang berbeda-beda untuk beberapa user agar terhindar dari penggunaan data yang ilegal oleh orang yang tidak bertanggung jawab

3. Pelatihan untuk pengguna baru sangat penting sekali hal tersebut agar dalm penggunaannya tidak terjadi kesalah

\section{UCAPAN TERIMA KASIH}

Penulis mengucapkan terima kasih kepada STMIK Tasikmalaya yang telah memberi dukungan financial terhadap penelitian ini.

\section{DAFTAR PUSTAKA}

[1] Praptiningsih, 2014, Sistem Pengolahan Objek Pajak Bumi Dan Bangunan Pada Kecamatan Kebonagung. Speed journal, volume 11 No 2. 
[2] Yusnidar Johan, Arik Sunarti \& Prasetya. 2015, Pengaruh Faktor-Faktor Yang Mempengaruhi Kepatuhan Wajib Pajak Dalam Melakukan Pembayaran Pajak Bumi Dan Bangunan Perdesaan Dan Perkotaan (Studi Pada Wajib Pajak Pbb-P2 Kecamatan Jombang Kabupaten Jombang). Jurnal Perpajakan (JEJAK), volume 1.

[3] Ely Suhayati., \& Siti Kurnia Rahayu. 2010. AUDITING, Konsep Dasar dan Pedoman Pemriksaan Akuntan Publik. Yogyakarta : Graha Ilmu.

[4] Kadir, A., 2008, Pengenalan Sistem Informasi. Yogyakarta: Andi..

[5] Kristanto, A., 2008, Perancangan Sistem Informasi dan apilkasinya. Yogyakarta: Gava Media.

[6] Azhar Susanto, 2004. Sistem Informasi Manajemen.Bandung: Linggar Jaya.

[7] Al-Fatta, H., 2007, Analisis dan Perancangan Sistem Informasi. Andi.

[8] Jogiyanto, H., 2005, Analisis dan Desain Sistem Informasi. Yogyakarta: Andi.

[9] Kristanto, I. H., 1994, Konsep \& Perancangan Database. Penerbit Andi, 